\title{
Lyophilisate and Suspension for Suspension for Injection Dosage Form
}

National Cancer Institute

\section{Source}

National Cancer Institute. Lyophilisate and Suspension for Suspension for Injection

Dosage Form. NCI Thesaurus. Code C149636.

Sterile lyophilisate and sterile suspension, both of which contain active substance(s), intended for the preparation of a suspension for injection, for veterinary use, by dispersing the lyophilisate in the suspension. 